University of Louisville

ThinkIR: The University of Louisville's Institutional Repository

Electronic Theses and Dissertations

$12-2008$

\title{
The use of the reducing agent $\mathrm{N}$-(2-Mercaptopropionyl)glycine to detoxify oxidized lipids in atherosclerotic lesions.
}

Nason P. Schooler 1974-

University of Louisville

Follow this and additional works at: https://ir.library.louisville.edu/etd

\section{Recommended Citation}

Schooler, Nason P. 1974-, "The use of the reducing agent N-(2-Mercaptopropionyl)glycine to detoxify oxidized lipids in atherosclerotic lesions." (2008). Electronic Theses and Dissertations. Paper 1280.

https://doi.org/10.18297/etd/1280

This Master's Thesis is brought to you for free and open access by ThinkIR: The University of Louisville's Institutional Repository. It has been accepted for inclusion in Electronic Theses and Dissertations by an authorized administrator of ThinkIR: The University of Louisville's Institutional Repository. This title appears here courtesy of the author, who has retained all other copyrights. For more information, please contact thinkir@louisville.edu. 
THE USE OF THE REDUCING AGENT

N-(2-MERCAPTOPROPIONYL)GLYCINE TO DETOXIFY OXIDIZED LIPIDS IN ATHEROSCLEROTIC LESIONS

By

Nason P. Schooler

B.S., Iowa State University, 2001

\author{
A Thesis \\ Submitted to the Faculty of the \\ Graduate School of the University of Louisville \\ in Partial Fulfillment of the Requirements \\ for the Degree of \\ Master of Science \\ Department of Pharmacology and Toxicology \\ University of Louisville \\ Louisville, Kentucky
}

December 2008 
THE USE OF THE REDUCING AGENT

N-(2-MERCAPTOPROPIONYL)GLYCINE TO DETOXIFY OXIDIZED LIPIDS IN ATHEROSCLEROTIC LESIONS

By

Nason P. Schooler

B.S., Iowa State University, 2001

A Thesis Approved on

December 1, 2008

By the following Thesis Committee:

Thesis Director 


\title{
ABSTRACT \\ The Use of the Reducing Agent N-(2-Mercaptopropionyl)glycine to Detoxify Oxidized Lipids in Atherosclerotic Lesions
}

\author{
Nason P. Schooler \\ December 1, 2008
}

The leading cause of death in the United States is cardiovascular disease, a result of atherosclerosis. The reducing agent $\mathrm{N}$-(2-Mercaptopropionyl)glycine (MPG) as been found to be an effective antioxidant therapy in a number of conditions, and our hypothesis is that it will be an effective agent in the detoxification of oxidized lipids in atherosclerosis. Our results indicate some protective effect, along with some toxicity at high doses, with refinement of the experimental model necessary before results can be conclusive. Nevertheless, antioxidant and aldehyde-quenching agents in general have been shown to be of benefit in the detoxification of oxidized lipids, and MPG is still therefore a good candidate. Since this is yet another mechanism used to combat the disease, we hypothesize that such reducing agents will complement other therapies quite effectively, providing an even more effective means of preventing the onset, as well as reversing the progression of atherosclerosis. 


\section{TABLE OF CONTENTS}

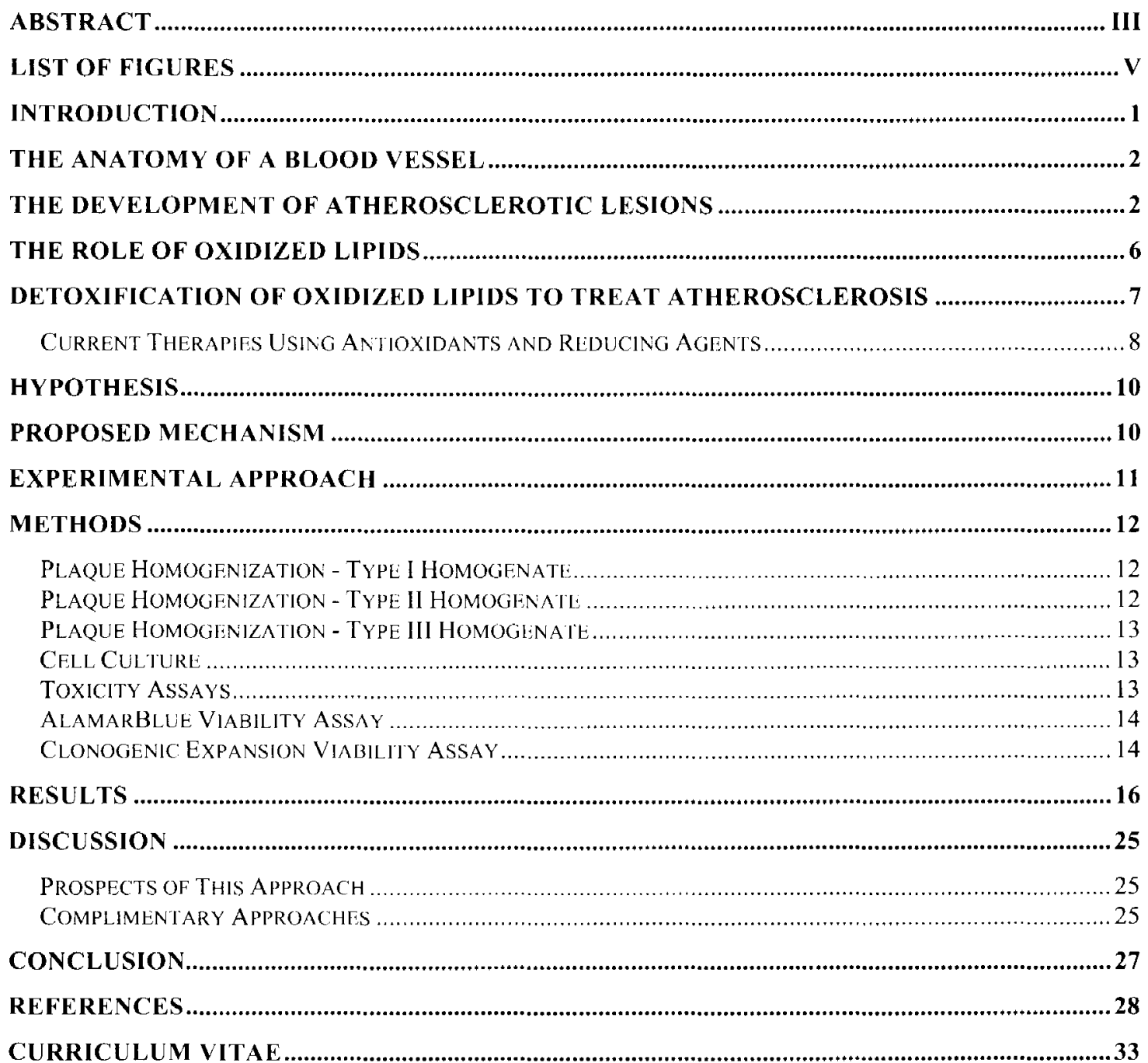




\section{LIST OF FIGURES}

\section{$\begin{array}{ll}\text { Figure } & \text { Page }\end{array}$}

1. The layers of tissue in an artery ........................................................... 2

2. The six types of lesions in the progression of atherosclerosis.......................... 3

3. The oxidative modification process...................................................... 6

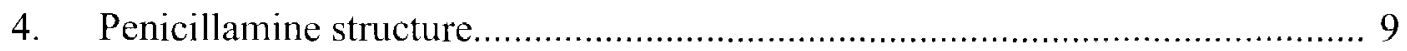

5. Penicillamine aldehyde quenching reaction.............................................. 9

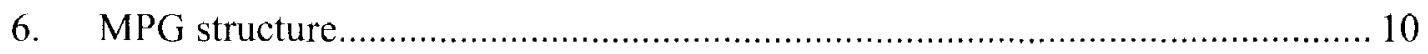

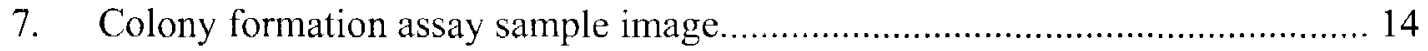

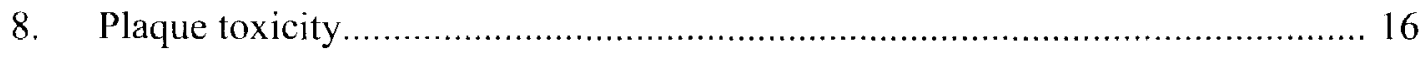

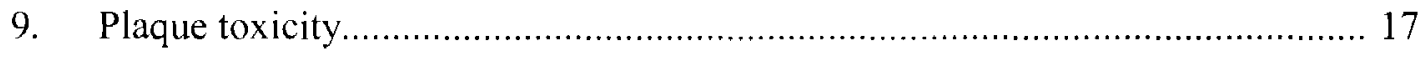

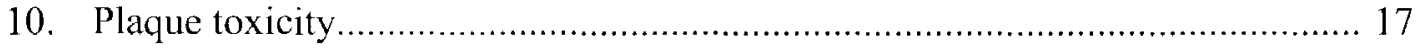

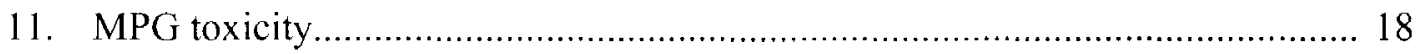

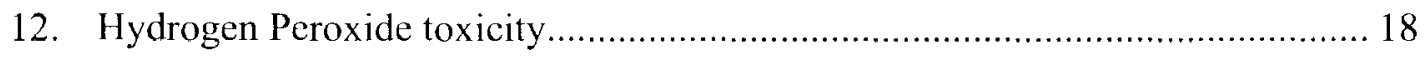

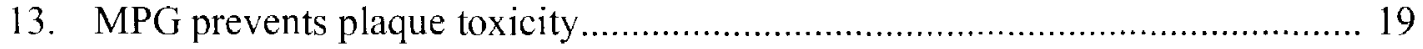

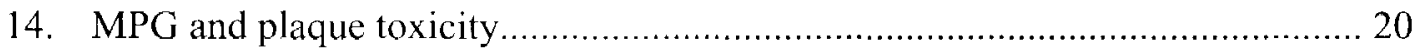

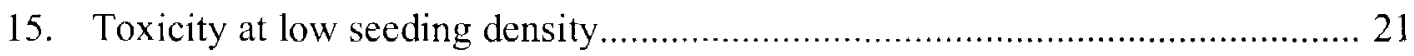

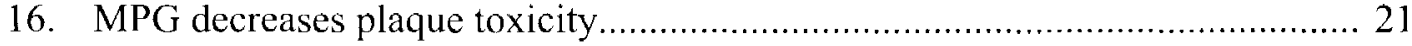

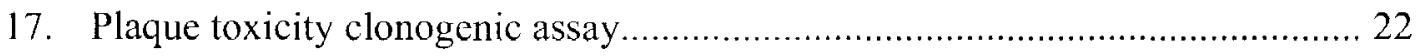

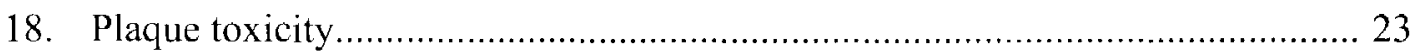




\section{INTRODUCTION}

Cardiovascular disease (CVD) is the leading cause of death in the US, the major contributor being coronary artery disease brought on by the onset of Atherosclerosis. ${ }^{4}$ Atherosclerosis is the pathology behind the two major components of cardiovascular disease; vascular disease leading to stroke, and coronary artery disease leading to heart attacks. The main characteristic of an atherosclerotic lesion is the deposition of cholesterol in medium to large arteries. In these critical vessels, the cholesterol deposits can grow over time, until the blood flow is hindered by the resulting occluded lumen, and heart attack and stroke result when the flow is completely blocked. Usually an actual rupture of a mature atherosclerotic plaque is the cause of sudden-onset heart attack or stroke. ${ }^{5}$

One of the most important factors influencing the development of atherosclerosis is the amount of cholesterol in circulation. This relationship between cholesterol and the development of atherosclerosis was recognized early on due to the genetic disorder Familial hypercholesterolemia. Heterozygote patients with this trait have a reduced number of LDL (low density lipoprotein - a common form of cholesterol packaged for transport in the bloodstream) receptors, and homozygous individuals have no LDL receptors. This is devastating particularly in the case of hepatic cells, which are responsible for removing cholesterol from the bloodstream. Thus, these individuals have high levels of circulating cholesterol, and correspondingly short lifespan, due to early- 
onset atherosclerosis and subsequent cardiovascular disease. Furthermore, cholesterollowering therapy has been found to greatly alleviate, and in some cases reverse the progression of atherosclerosis. Key among these are the statins - a group of compounds targeting the key regulatory enzyme in cholesterol synthesis: HMG-CoA reductase. ${ }^{6}$

\section{The Anatomy of a Blood Vessel}

Before we begin our discussion of the features and development of atherosclerotic lesions, it will help to describe the basic features of a normal artery. Figure 1 depicts the three principal layers which surround the arterial lumen. The intima consists of a monolayer of vascular endothelial cells on a second layer of mostly smooth muscle cells in a substrate of extracellular matrix. The media is made up of further layers of smooth

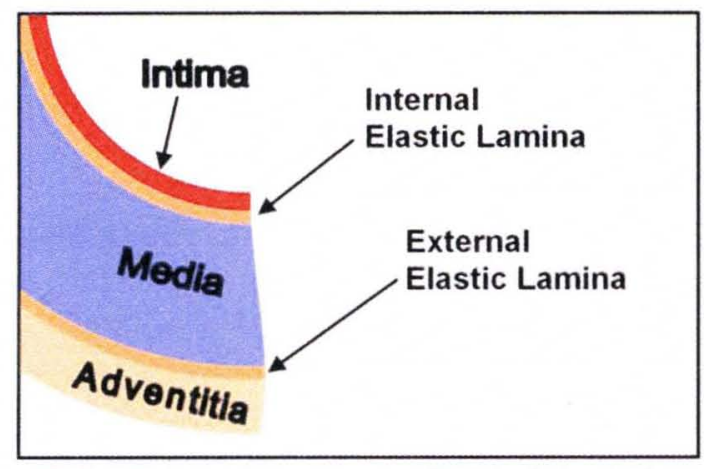

Figure 1 - The layers of tissue in an artery. The intima is closest to the lumen, while the Adventitia makes up the outer surface of the vessel. muscle cells, and the adventitia, consisting of collagen, fibroblasts, smooth muscle cells and elastin. Thin layers of elastin also separate the other layers, making up the internal and external elastic laminas.

\section{The Development of Atherosclerotic Lesions}

Despite the fact that the relationship between cholesterol in circulation, cholesterol deposits in arteries and atherosclerosis is well known, the fundamental genesis of these deposits has not been definitively identified. What is known for certain is that fatty streaks - small deposits of cholesterol in the intima - begin forming at an early age in the arteries of most denizens of developed societies. Preceding the appearance of these fatty streaks, is a thickening of the intima - termed type I lesions, these instances of thickening are thought to be an adaptive response to shear stresses 
along the vessel wall and to tensile stresses against the wall. They are denoted as areas of eccentric thickening, as opposed to uniform thickening of the intima, called diffuse thickening, which does not directly correlate with atherosclerosis. While atherosclerotic lesions form at these sites, such areas of eccentric thickening occur whether or not atherosclerosis is present. The same stresses that result in eccentric thickening due to irregularities in the fluid flow also apparently contribute to cholesterol deposition in the intima, if serum cholesterol levels are high enough. Thus lesions form earlier at these locations than elsewhere in the arteries, and they are therefore associated with the initial appearance of fatty streaks, and subsequently the classic locations of advanced lesions. ${ }^{7}$

Figure 2 shows the six morphological stages ${ }^{3}$ recognized as making up the classic development of an

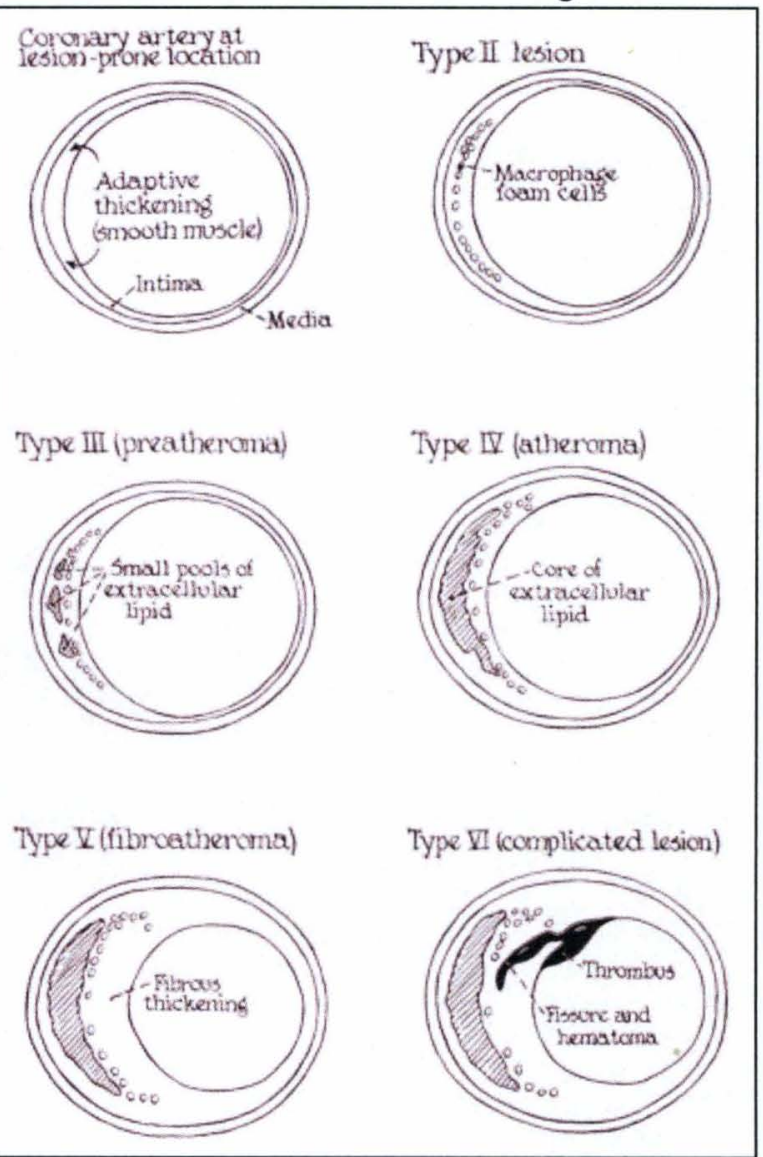

Figure 2 - The six types of lesions in the progression of atherosclerosis. (From Stary et al. ${ }^{3}$ ) atherosclerotic lesion. Following the adaptive thickening of the intimal smooth muscle region, There is an increase in the concentration of deposited plasma components. Proteins, HDL and LDL, along with most plasma constituents, deposit within the intima throughout the arteries in proportion to their concentrations in the bloodstream and their molecular weights. In regions of eccentric thickening, however, macrophages, LDL, and 
the other plasma components are more concentrated. Since the endothelial layer directly adjacent to the arterial lumen is very amenable to such deposition, and since a large contributor seems to be the natural fluid flow in the lumen, it naturally follows that areas which thicken in response to excess tensile stress will accumulate additional material as a result of such stress. Thus, in these areas of eccentric thickening in normal healthy arteries the seeds of atherosclerosis are sown. The essential players are there - excess cholesterol in the form of LDL and macrophages to take them up and form foam cells. The current predominant view is that accumulation of LDL leads to inflammation, thus initiating the onset of atherosclerosis. ${ }^{8}$ The oxidization of LDL and the subsequent involvement of inflammation and macrophages in foam cell formation are key factors determining whether a fatty streak will remain benign, or develop into more advanced types of atherosclerotic lesions. Such oxidization can be the target for a variety of different interventions, which will be discussed below.

Type II lesions are characterized by the formation of fatty streaks made up of macrophages that have taken up excessive amounts of lipids (foam cells). Fatty streaks are not inherently pathologic, and may never turn into type III lesions, or they may even regress on their own. In fact, each of the six types of lesions represent inherently stable entities which may remain unchanged for long periods of time, or may continue on to become more advanced lesions. ${ }^{9}$ In the event that the fatty streaks continue to grow due to the accumulation of foam cells, type III lesions become evident. These are characterized by the appearance of extracellular lipid patches, which are the result of macrophage necrosis, and can readily accumulate by the age of 10 years. By the mid 30's they can account for one third of the surface area of the aorta. ${ }^{10}$ 
Type IV lesions are considered full atheromas, conisisting of a large, contiguous area of extracellular lipids within the intima. Eventually, these areas can develop a hard, fibrous cap, at which point they are type $\mathrm{V}$ fibroatheroma lesions. Such lesion caps form mostly in the mid 30 's to mid 40 's, the vessels involved being predominantly abdominal aorta, coronary and carotid arteries. The main distinguishing factor between types IV and $\mathrm{V}$ is that of new structural fibrous material forming prominent connective tissue that was not present before. This tissue can be extensive, composed of several layers of lesions that form in a step-by-step fashion. Following the formation of an initial type $\mathrm{V}$ lesion, the flow geometry may change significantly, resulting in new deposition of tissue in a nearby, partially overlying area. This process can occur repeatedly, together with multiple thrombotic events and micro-hemorrhages in capillaries throughout the lesion, resulting in an irregularly stacked conglomeration of overlapping extracellular lipid cores separated by fibrous walls. By the time a lesion has reached type $\mathrm{V}$, the original structure of the vessel has become significantly altered, resulting in a significant rearrangement of smooth muscle and endothelial cells, as well as rearrangement and formation of new areas of connective tissue. ${ }^{3}$

The most devastating pathologies arise from Type VI lesions, which arise when the shoulder region between the fibrous cap and the normal artery wall ruptures. Type VI lesions often contain evidence of previous fissuring in this area which has subsequently been patched over. At this point, the lesion is in danger of significant rupture and resulting thrombosis and occlusion of the artery at any time.

The goal of preventive measures and even therapy is to intervene before lesions progress to this final stage. As would be naturally expected, earlier is better, and simple 
modifications of the diet can result in complete reversion of type I, II and III lesions. ${ }^{9}$

One of the earliest contributing factors in the development of foam cells is the appearance of oxidized lipids. Thus much research has been done to elucidate the underpinnings of this process, as well as where lipids are oxidized, and how the deleterious interaction with macrophages takes place. ${ }^{11}$

\section{The Role of Oxidized Lipids}

LDL has not been found to be an effective contributor to atherosclerosis in its normal state. Macrophages have been found to be quite reluctant to take up normal LDL. However, the LDL can become modified into a form that is highly atherogenic. Once LDL is oxidized, macrophages take it up approximately 40 times faster than normal LDL - and by a different class of receptors, called scavenger receptors. ${ }^{12}$ While acetylation was carried out in initial in vitro experiments ${ }^{13}$ to demonstrate this rapid uptake, this modification is not involved in vivo. Oxidative modification of LDL does happen in the

living organism however, and subsequent investigations showed that macrophages took

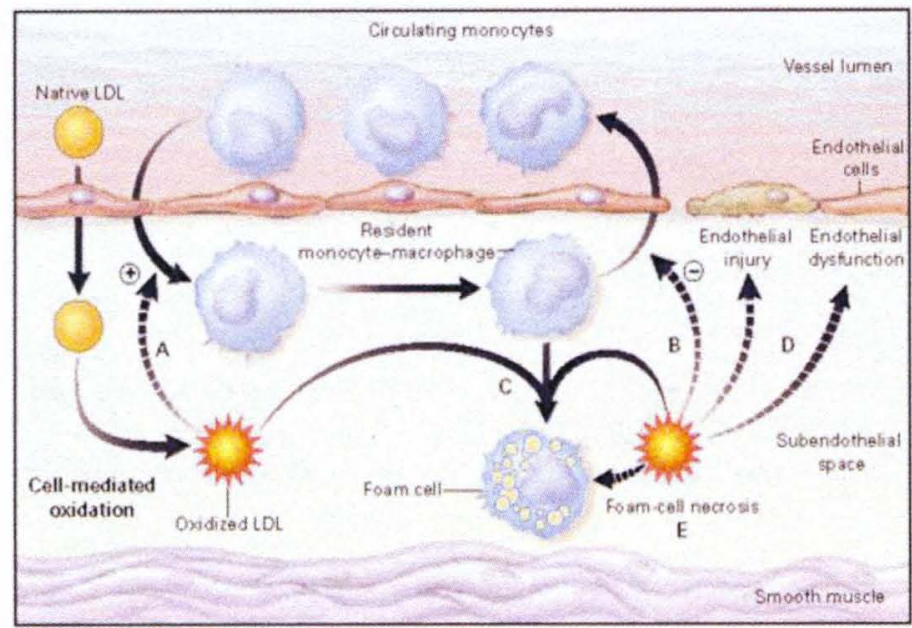

Figure 3 - The Oxidative Modification Process

LDL trapped in the intima becomes oxidized by vascular smooth muscle cells, endothelial cells and macrophages. A. This attracts more macrophages due to their chemotactic attraction to oxidized lipids. B. Monocytes are also prevented from leaving the intimal space. C. Nondegradable oxidized lipids accumulate in the lysosomes of macrophages, which become foam cells. D. Endothelial cells also become injured and dysfunctional due to the presence of oxidized LDL. E.
Accumulation of indigestible lipids in foam cells eventually leads to apoptosis and necrosis. (From Diaz et a.) $)^{2}$ up such LDL as readily as the acetylated version. $^{14}$

Furthermore, oxidized LDL has been found to contribute to atherogenesis by its cytotoxicity to both endothelial cells and macrophages, by preventing macrophages from leaving 
the intima, and by aiding the attraction of circulating monocytes into the intima in the first place. ${ }^{15}$ The role of oxidization of LDL in the development of atherosclerosis is summarized in Figure 3.

When LDL is trapped in the intima and becomes oxidized by surrounding cells, the lysine residues of apolipoprotein-B-100 (one of the protein components of LDL) become more negatively charged. Haberland et al. have demonstrated that such malondialdehyde-induced modifications result in crosslinks which make the molecule amenable to scavenger-receptor uptake, ${ }^{16}$ eventually leading to the formation of foam cells. ${ }^{17}$ LDL can also be oxidatively modified independently of apolipoprotein-B-100. Such minimally modified LDL induces the production of monocyte chemotactic proteins in endothelial cells and also smooth muscle cells ${ }^{18}$, and overall inducing a proinflammatory response in the tissue. ${ }^{19}$ Without the necessary chemotaxis receptor, the macrophages of mice do not respond accordingly, and the mice have been found to be resistant to atherosclerosis. ${ }^{20}$ Monocytes and T-lymphocytes are also highly chemotactic in response to more heavily oxidized $\mathrm{LDL}^{21}$ (termed oxLDL), which also stimulates the production of auto-antibodies and immune complexes which facilitate macrophage ingestion of LDL. ${ }^{22}$ Inflammation can also promote further oxidation of LDL, thus expanding the lesion.

\section{Detoxification of Oxidized Lipids to Treat Atherosclerosis}

Since oxidation of LDL has been found to be quite deleterious and inherently foundational in the etiology of atherosclerosis, the search for effective methods to detoxify this substance has been and continues to be a major field of study, ${ }^{23}$ 


\section{Current Therapies Using Antioxidants and Reducing Agents}

Vitamin $\mathrm{E}$ has been one of the most thoroughly investigated antioxidant therapies for atherosclerosis. While a number of small clinical trials have shown promising results, all large-scale clinical trials have shown no beneficial effect of vitamin $E$ in the treatment of heart disease. ${ }^{24}$ In several animal models, and in certain special conditions, such as 12/15-lypoxygenase gene inhibition, vitamin $\mathrm{E}$ has been shown to be quite beneficial in this regard. ${ }^{25}$ It seems that in certain groups, for instance those in which oxidative stress is a system-wide pathology, such antioxidant administration can be quite beneficial. Overall, vitamin $\mathrm{E}$ has been proven to be anti-oxidant or pro-oxidant or even neutral in atherogenesis, depending on myriad other factors. ${ }^{26}$

Other antioxidants which have been assayed for therapeutic intervention in atherogenesis include Glutathione ${ }^{27}$, Probucol and several analogs, individual polyphenols and mixtures of polyphenols, and combination therapy using vitamin $\mathrm{E}$ in conjunction with Selenium, vitamin A, or vitamin $\mathrm{C}^{23}$ The role of human alto-ketoreductase in protection against toxic aldehydes has also been examined, ${ }^{28}$ with an eye towards potential therapies involving similar adehyde reduction. Several types of aldehyde groups resulting from lipid peroxidation have been lumped together into the category of reactive carbonyl species (RCS). These include $\alpha, \beta$-unsaturated aldehydes, di-aldehydes, and keto-aldehydes. Since RCS are widely prevalent in atherosclerotic lesions despite the presence of large amounts of antioxidants such as vitamins $\mathrm{C}$ and $\mathrm{E}$ in the vessel wall, an alternative strategy has been developed to detoxify them - namely, the use of agents which sequester and thus nullify carbonyls directly. ${ }^{29}$ These sacrificial nucleophiles directly attack and quench aldehyde groups, rendering RCS unable to damage other biomolecules. ${ }^{30,31}$ 
One particularly promising subset of these aldehyde quenching agents includes compounds containing a reactive thiol group. Examples include $\mathrm{N}$-acetyl cysteine (NAC) and several analogs, ${ }^{32}$ as well as other compounds containing cysteine such as s-allyl cysteine, s-ethyl cysteine, s-methyl cysteine, and s-propyl cysteine. ${ }^{33}$ Also worthy of note, are combination therapies involving thiol-containing compounds, such as the combination of $\mathrm{N}$-acetyl cysteine and taurine, ${ }^{34}$ Of particular interest is the thiol-

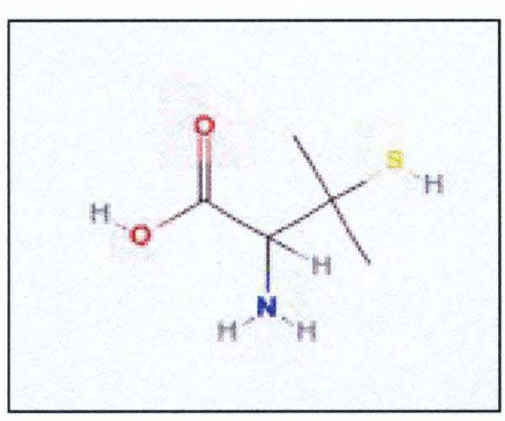

Figure 4 - Penicillamine structure. The sulfhydril (thiol) group readily reacts with aldehydes, forming harmless thiazolidine derivatives.

(From PubChem) containing small molecule compound D-Penicillamine

(3,3-dimethyl-D-cysteine, see Figure 4), which was

identified using a new screening process for aldehydequenching agents developed by Wondrak and colleagues

at the University of Arizona Tucson. ${ }^{1}$ D-Penicillamine reacts with aldehyde groups to form benign thiazolidine

derivatives, which are easily cleared from the system. This reaction is shown in Figure 5. The nucleophilic thiol group attacks the carbonyl carbon, freeing the oxygen as water and forming a covalent linkage at the former site of the aldehyde. Penicillamine is used therapeutically to treat a variety of pathologies, including rheumatoid arthritis (as a

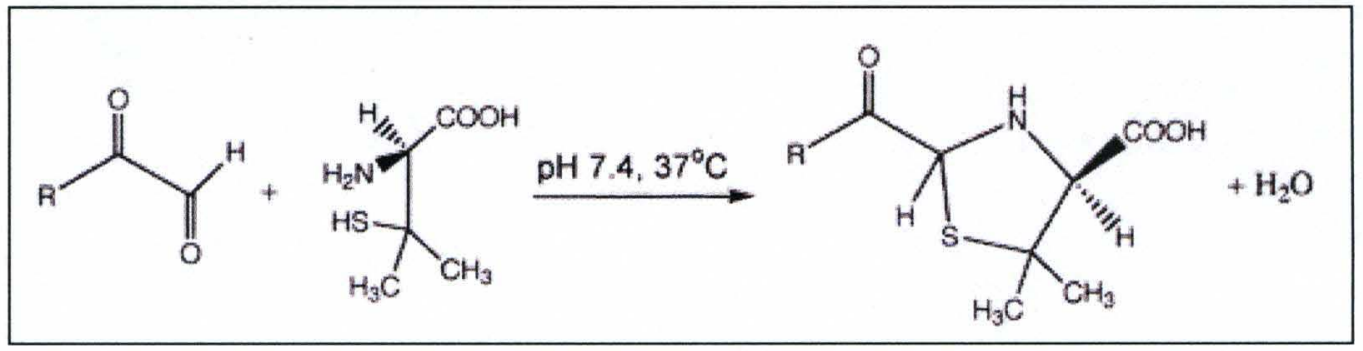

Figure 5 - Penicillamine aldehyde quenching reaction. The sulfhydril (thiol) group readily reacts with aldehydes, forming harmless thiazolidine derivatives. (From Wondrak et al. ${ }^{1}$ )

secondary medication), metal ion intoxication, cystinuria and Wilson's disease (copper storage disease). ${ }^{35}$ 
Another similar small-molecule compound containing such a reactive thiol group is N-(2-Mercaptopropionyl)glycine (MPG), which is also known by the names Acadione, Capen, Captimer, Epatiol, Meprin (detoxicant), Mucolysin, Sutilan, Thiola, Thiolpropionamidoacetic acid, Thiopronin, Thiopronine, Thiosol, Tioglis, Tiopronin, and Vincol. MPG is used to treat cystinuria, ${ }^{36}$ arthritis, ${ }^{37}$ a variety of drug toxicities associated with damaging carbonyls and reactive oxygen species (ROS) $)^{38,39}$, and also demonstrates significant protection against ischemia/reperfusion injury. ${ }^{40}$ It is also used to scavenge ROS produced by ionizing radiation, ${ }^{41}$ as well as radiation-produced lipid peroxidation. ${ }^{42}$

\section{Hypothesis}

Such protective effects against lipid

peroxidation, together with the similar structure and

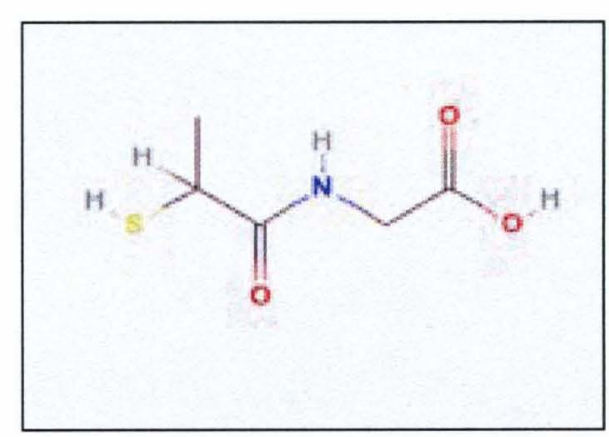

Figure 6 - MPG structure. The sulfhydril (thiol) group readily reacts with aldehydes, forming harmless
thiazolidine derivatives. function to D-Penicillamine, an already proven thiazolidine derivatives.
(From PubChem)

aldehyde quencher, have led to the hypothesis that MPG may offer significant aldehyde quenching in atherosclerotic lesions and thus protection against carbonyl toxicity in oxidized LDL.

\section{Proposed Mechanism}

MPG has been found to be a very effective free radical scavenger, and also iron chelation and glutathione sparing have also been proposed as mechanisms behind the protective effects conferred by MPG. ${ }^{43}$ The susceptibility of its reactive sulfhydril group, which is readily oxidized, makes it suited to a number of applications in ameliorating oxidative damage. In particular, such thiol-containing small molecules, such as D- 
Penicillamine, have been demonstrated to be highly effective quenchers of reactive aldehydes. Thus, the mechanism we propose as being most highly applicable to detoxification of atherosclerotic plaques is that of aldehyde quenching, whereby its sulfhydril group reacts directly with the aldehyde, forming thiazolidine derivatives which are nonreactive.

\section{Experimental Approach}

To test the efficacy of MPG as a protective agent, we have used the following experimental model: Soft plaques obtained from carotid atheroma lesions are isolated and homogenized in ethanol. Murine-derived J774 macrophage-like cells, which have been shown to respond to toxicity of atherosclerotic plaques ${ }^{44-46}$, are exposed to varying concentrations of this homogenate, both with and without the addition of MPG. Standard culture viability assays are then used to determine the degree of protection conferred against plaque-induced cell death. 


\section{METHODS}

Plaque Homogenization - Type I Homogenate

Samples of waste from percutaneous atherectomy procedures were obtained (IRB \#286.07) from Dr. Timothy Godshall, MD at University Hospital in Louisville, KY. These were very dilute suspensions of atheroma lesion components suspended in saline. The saline suspensions were centrifuged at $20,000 \mathrm{~g}$ for 30 minutes. The pellet was then weighed, suspended in $2 \mathrm{ml} 100 \%$ ethanol, and homogenized in a Wheaton glass-on-glass homogenizer. After one hour of homogenization, the plaque suspension was decanted off, and the remaining non-homogenizable components were weighed and then discarded. The suspension was further homogenized using the tightest-fitting rod for the homogenizer. After several hours of homogenization, the resulting suspension was added to additional ethanol to make a $10 \mathrm{mg} / \mathrm{ml}$ stock suspension.

Plaque Homogenization - Type II Homogenate

Atheromatous plaque samples from carotid endarterectomy surgical waste were obtained immediately following procedures performed by Dr. Timothy Godshall, MD at University Hospital in Louisville, KY. The entire atheroma that had been removed in the endarterectomy was weighed after minimal drying to obtain the wet weight. This intact piece was placed in a glass-on-glass Wheaton homogenizer along with $1-2 \mathrm{ml}$ of $100 \%$ ethanol, depending on the size of the atheroma. After one hour of homenization, the plaque suspension was decanted off, and the remaining non-homogenizable components 
were weighed and then discarded. The suspension was further homogenized using the tightest-fitting rod for the homogenizer. After several hours of homogenization, the resulting suspension was added to additional ethanol to make a 5 to $100 \mathrm{mg} / \mathrm{ml}$ stock suspension, depending on how much material was isolated.

Plaque Homogenization - Type III Homogenate

In an effort to isolate more gelatinous plaque from the carotid endarterectomy surgical waste samples without exposing other components to homogenization, the gelatinous plaque components were scraped off using a scalpel. The isolated material was then weighed and homomogenized as before, except no decanting/removal of nonhomogenizable material was necessary. We also attempted to maximize the concentration of our stock solutions, giving between 75 and $100 \mathrm{mg} / \mathrm{ml}$, depending on how $\mathrm{m}$ much material was isolated.

\section{Cell Culture}

J774 (Sigma \#85011428) cells are derived from mouse monocyte/macrophage cells and form semi-adherent layers when cultured. Cells were cultured in Dulbecco's Modified Eagle's Medium (DMEM) with 2mM L-glutamine (Sigma \#D6429) and 10\% Fetal Bovine Serum (FBS) at $37^{\circ} \mathrm{C}$ in a $\mathrm{CO}_{2}$ incubator.

\section{Toxicity Assays}

24 or 96-well (24-well Costar Clear, Corning \#3473, or 96-well Costar black w/ clear bottom, Corning \#3603) plates were seeded between $10 \%$ and $50 \%$, depending on the experiment, with $\mathrm{J} 774$ cells and incubated at $37^{\circ} \mathrm{C}$ in a $\mathrm{CO}_{2}$ incubator for $12 \mathrm{~h}-24 \mathrm{~h}$, depending on the experiment, at which point plaque homogenate, hydrogen peroxide and MPG were added. Plates were then incubated for another $4 \mathrm{~h}-24 \mathrm{~h}$, depending on the 
experiment, at which time the medium was changed and replaced with fresh medium containing $10 \%$ AlamarBlue indicator. Following a $2 \mathrm{~h}-4 \mathrm{~h}$ incubation period, depending on the experiment, the plate was read with a spectrofluorometer to determine cell viability based on metabolic reduction of AlamarBlue.

\section{AlamarBlue Viability Assay}

AlamarBlue (ABD Serotec \#BUF012B) was chosen because of its simplicity and reliability. A $10 \%$ solution of AlamarBlue in normal culture medium is added to cells, which under normal metabolic activity reduce the originally oxidized nonfluorescent blue form of the indicator to the reduced fluorescent red form. 4 hours usually falls within the linear phase of this reduction process, but readings at several different time points are taken to verify that the reading chosen is within this range. Quantitation via the spectrofluorometric plate reader ensures reliability and consistency. Viability is expressed as the percent reduction of the indicator in test groups vs. the percent reduction in controls.

Clonogenic Expansion Viability Assay $10 \mathrm{~cm}$ polystyrene tissue culture plates were seeded with 200 cells each and incubated in DMEM at $37^{\circ} \mathrm{C}$ for 5 days. Medium was then removed, and plates were washed with phosphate-buffered saline (PBS). Cells were then fixed in a 50/50 PMS/Methanol solution for 2 minutes, and then $100 \%$ Methanol for 10 minutes.

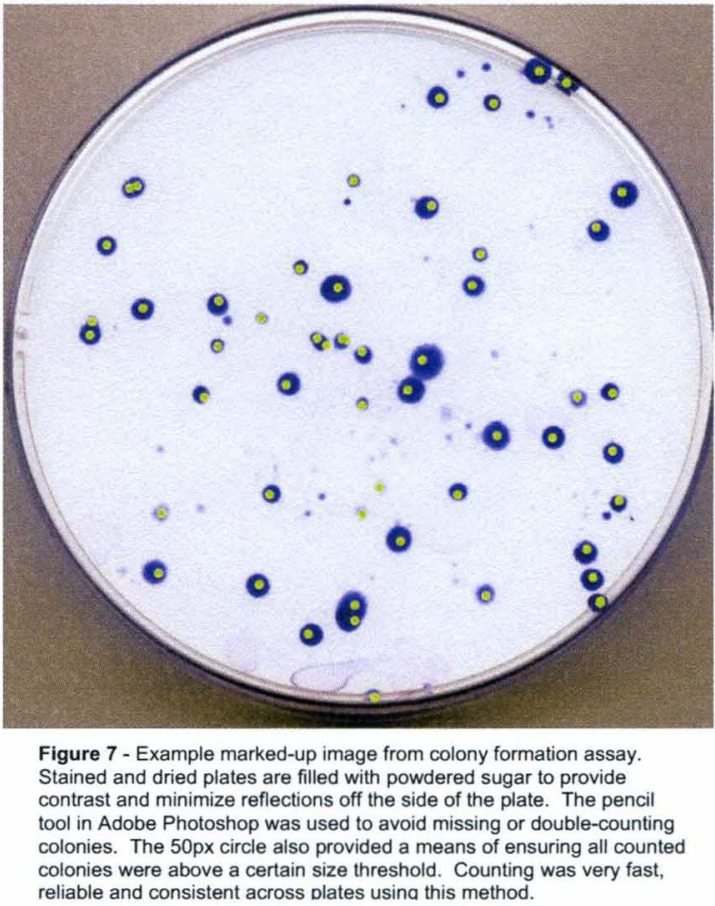


Methanol was then removed, and the plates allowed to dry for 30 minutes. Cells were then stained with Gentian Violet stain for 30 minutes, rinsed with tap water, and allowed to air dry for 3 hours. Plates were then filled with powdered sugar to provide clean reads and scanned on an HP flatbed scanner. Colonies were then counted in Adobe Photoshop software, using the pencil tool with a 50pixel contrasting yellow circle to mark each colony (Figure 7), which ensured accuracy in counting and provided a consistent threshold for colony size. 


\section{RESULTS}

In order to verify plaque toxicity in our hands, a type I plaque homogenate (see Methods section above for details) was made from dilute plaque gruel samples (see Figure 8). The resulting homogenate was estimated to be $10 \mathrm{mg} / \mathrm{ml}$ gruel, and $0.5 \%$ of this added to test wells of a $24-w e l l$ plate, giving a $50 \mu \mathrm{g} / \mathrm{ml}$ final plaque concentration.

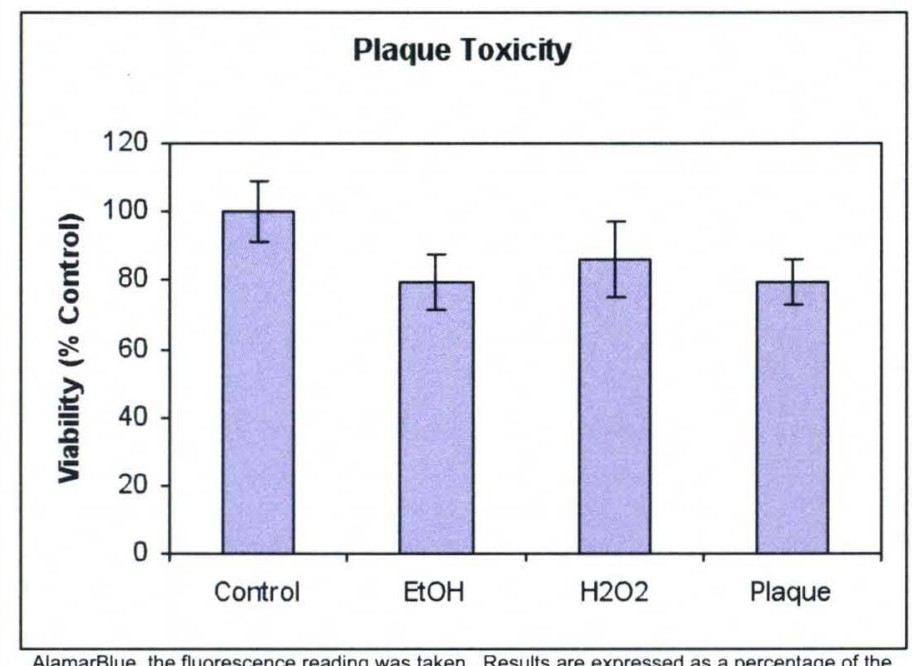

viability of control cells, based upon the degree of AlamarBlue reduction.
$0.5 \%$ ethanol was used as a

vehicle control. There were 24

hours between seeding, adding

toxins, and adding the

AlamarBlue indicator. The

plate was read 4 hours after

AlamarBlue was added.

Mostly due to the fact that the

plate was too overgrown by the time the read was taken, not much toxicity could be seen, even with our $100 \mu \mathrm{M} \mathrm{H}_{2} \mathrm{O}_{2}$ positive control. To address these issues, the next assay (Figure 9) was done using a $25 \%$ seeding density and more concentrated hydrogen peroxide, to be sure the positive control was showing up. This resulted in significant vehicle toxicity appearing from the ethanol, and virtual complete cell killing from the 1mM hydrogen peroxide. 


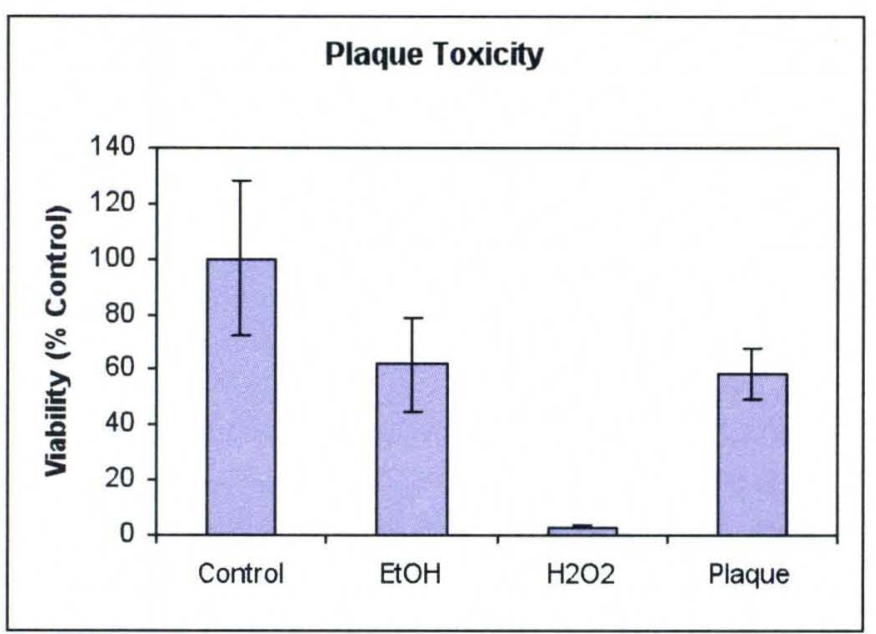

As before, no significant

plaque toxicity apart from the

vehicle was evident.A subsequent

experiment was run (Figure 10) to

reduce variability through more

consistent handling, and to verify

Figure 9 - Plaque Toxicity Assay. A 24 well Costar plate was seeded at $25 \%$ confluence with $\mathrm{J} 774$ Cells. 24 hours later, plate was treated with $0.5 \%$ of the $10 \mathrm{mg} / \mathrm{ml}$ plaque homogenate. $0.5 \%$ Ethanol as a vehicle control and $100 \mu \mathrm{M} \mathrm{H}_{2} \mathrm{O}_{2}$ as a positive control. Six wells were used for each condition to provide replicates for improved statistical significance. 24 hours after that, medium was exchanged for new medium containing $10 \%$ AlamarBlue. After $4 \mathrm{~h}$ incubation with AlamarBlue, the fluorescence reading was taken. Results are expressed as a percentage of the viability of control cells, based upon

the degree of AlamarBlue reduction.

the result with higher ethanol and plaque concentrations. A 24 well Costar plate was seeded at $50 \%$

confluence with J774 Cells. 24 hours later, the plate was treated with $1 \%$ of the $10 \mathrm{mg} / \mathrm{ml}$ plaque homogenate. $1 \%$ Ethanol as a vehicle control and $1000 \mu \mathrm{M} \mathrm{H} \mathrm{H}_{2} \mathrm{O}_{2}$ as a positive

control. Six wells were used for each condition to provide replicates for improved statistical

significance. 24 hours after that, medium was exchanged for new medium containing $10 \%$

AlamarBlue. After $4 \mathrm{~h}$ incubation with AlamarBlue, the fluorescence reading was taken. Toxicity was still not very evident, but plate was quite overgrown by the time the reading was taken, again confounding the results. Interestingly, when the plate was subsequently left in the
Plaque Toxicity

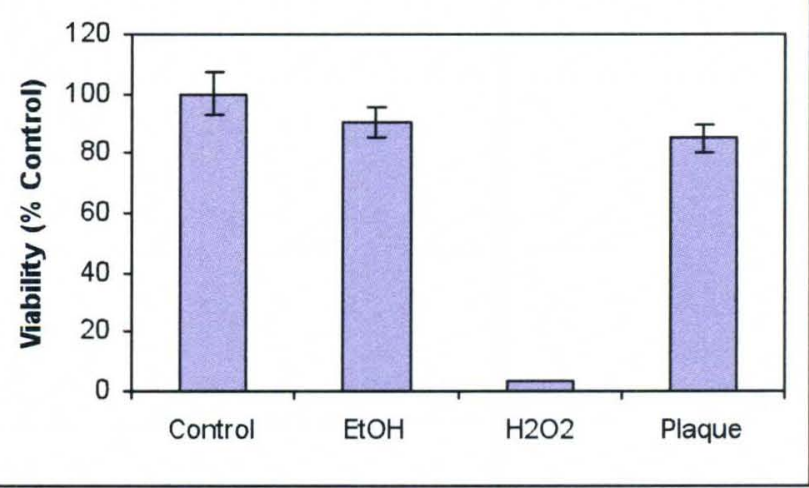

Figure 10 - Plaque Toxicity Assay. A 24 well Costar plate was seeded at $50 \%$ confluence with $\mathrm{J} 774$ Cells. 24 hours later, plate was treated with $0.5 \%$ of the $10 \mathrm{mg} / \mathrm{ml}$ plaque homogenate. $0.5 \%$ Ethanol as a vehicle control and $1000 \mu \mathrm{M} \mathrm{H} \mathrm{H}_{2}$ as a positive control. Six wells were used for each condition to provide replicates for improved statistical significance. 24 hours after that, medium was exchanged for new medium containing $10 \%$ AlamarBlue. After $4 \mathrm{~h}$ incubation with AlamarBlue, the fluorescence reading was taken. Results are expressed as a percentage of the viability of control cells, based upon the degree of AlamarBlue reduction. 


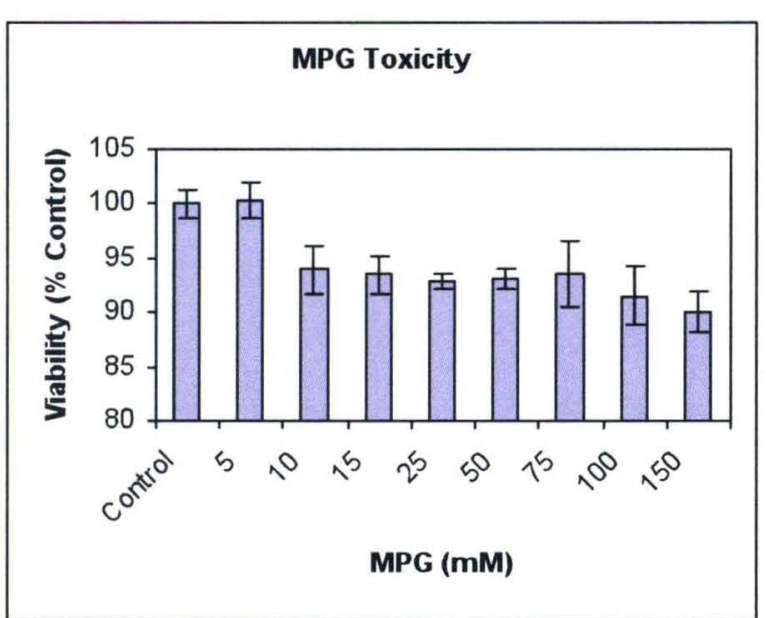

Figure 11 - MPG Toxicity Assay. A 96-well plate was seeded at $10 \%$ confluence and allowed to incubate for $24 \mathrm{~h}$, at which point it was approximately $20 \%$ confluent. MPG was added in various concentrations, ranging from $5 \mathrm{mM}$ to $150 \mathrm{mM}$. Cells were incubated with MPG for $48 \mathrm{~h}$, and then a standard AlamarBlue assay was performed, with a reading taken after $4 \mathrm{~h}$ incubation. Results are expressed as a percentage of the viability of control cells, based upon the degree of AlamarBlue reduction. incubator over the weekend, the cells in

plaque-treated wells were completely

detached, while ethanol and control

wells were fine, containing an

overgrown layer of cells.

MPG and hydrogen peroxide

toxicity assays (Figures 11 and 12) were done in order to find the appropriate

levels for our model. In the case of

MPG, we were looking for minimal toxicity. A 96-well plate was seeded at $10 \%$

confluence and allowed to incubate for $24 \mathrm{~h}$, at which point it was approximately $20 \%$

confluent. MPG was added in various concentrations, ranging from $5 \mathrm{mM}$ to $150 \mathrm{mM}$

(Figure 11). Cells were incubated with MPG for 48h, and then a standard AlamarBlue

assay was performed, with a

Hydrogen Peroxide Toxicity

reading taken after $4 \mathrm{~h}$

incubation. $5 \mathrm{mM}$ was

completely non-toxic, while

the higher concentrations all

decreased viability somewhat.

Based upon this finding, we

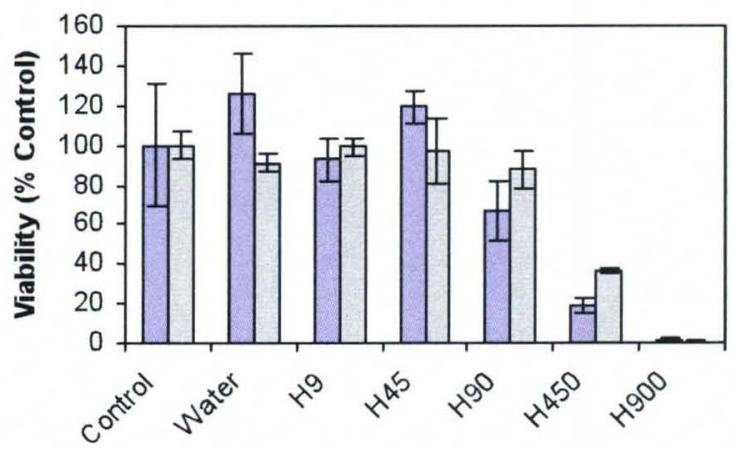

chose $5 \mathrm{mM}$ as the ideal

Figure $12-\mathrm{H}_{2} \mathrm{O}_{2}$ Toxicity Assay. $\mathrm{H}_{2} \mathrm{O}_{2}$ was added to $25 \%$ confluent 24 -well plates in pre-

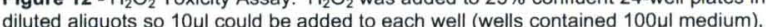
Concentrations ranged from $9-900 \mu \mathrm{M}$. 10 $10 \mathrm{l}$ water was added as a vehicle control. Then plates were incubated for $20 \mathrm{~h}$, when we changed medium to add $10 \%$ Alamar blue. Reading was taken $\mathbf{4}$ hours later. Results are expressed as a percentage of the viability of control cells, based upon the degree of AlamarBlue reduction.

concentration for MPG. 
Due to earlier problems in finding the appropriate $\mathrm{H}_{2} \mathrm{O}_{2}$ concentration for use as a positive control, an $\mathrm{H}_{2} \mathrm{O}_{2}$ toxicity assay was performed (Figure 12 ). $\mathrm{H}_{2} \mathrm{O}_{2}$ was added to $25 \%$ confluent 24 -well plates in pre-diluted aliquots so $10 \mu$ l could be added to each well (wells contained $100 \mu \mathrm{l}$ medium), $10 \mu \mathrm{l}$ water was added as a vehicle control to detect possible effects from medium dilution. 24-well plates were used instead of 96-well so that $\mathrm{H}_{2} \mathrm{O}_{2}$ could be pipetted directly into each well, to avoid earlier problems with depletion when using basins and a multichannel pipettor for the 96-well plates.

Following addition of toxin, plates were incubated for $20 \mathrm{~h}$, at which time the J774 cells were about $75 \%$ confluent in the most proliferative wells. Medium was then changed to add 10\% Alamar blue. The reading was taken 4 hours later. Despite quite a bit of variability, an $\mathrm{LD}_{50}$ of approximately $150 \mu \mathrm{M} \mathrm{H}_{2} \mathrm{O}_{2}$ was apparent. In subsequent experiments, we therefore used $100 \mu \mathrm{M}$ or $200 \mu \mathrm{M}$, depending on the cell seeding density of the experiment at hand.

Building on the experience gleaned from the previous assays, a larger scale

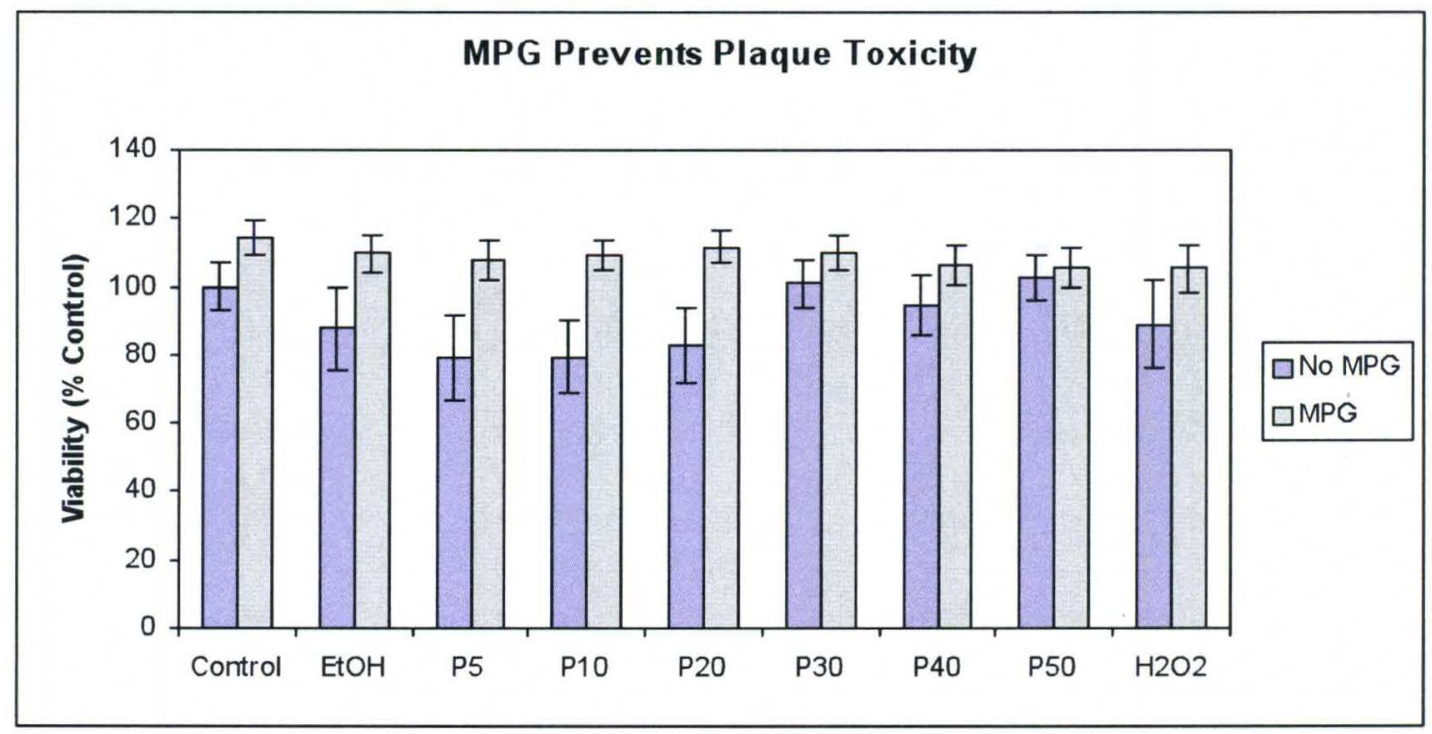

Figure 13 - MPG Experiment. 6 separate 96-well plates each contained a duplicate experiment. Results are from composite data from all 6 plates, representing 24 indivdual tests for each condition. Error bars represent $95 \%$ confidence intervals. $1 \%$ Ethanol was used as a vehicle and plaque concentrations of $5 \mu \mathrm{g} / \mathrm{ml}$ through $50 \mu \mathrm{g} / \mathrm{ml}$ were tested. Hydrogen Peroxide was $200 \mu \mathrm{M}$. Results are expressed as a percentage of the viability of control cells, based upon the degree of AlamarBlue reduction. 
experiment was done to test MPG alleviation of plaque toxicity using 696 -well plates as replicates. Each plate contained a complete set of assays, with 4 wells being allotted to each condition (Figure 13). Fresh type II plaque homogenates were used (see Methods section above for details), and plates were seeded at $20 \%$ confluence. Unfortunately this still was not enough time, over the course of a $60+$ hour experiment, to prevent the wells from becoming overgrown. Thus results were once again rather obfuscated. Despite these setbacks, due to the high number of replications a somewhat consistent trend could be seen where evident toxicity at lower plaque concentrations was alleviated by the addition of MPG. Higher plaque concentrations proved inexplicably stimulatory to a certain degree, but MPG rescue, and even stimulation in the case of controls, could be seen across the board.

In order to see more toxicity, (Figure 14), 96-well plates were seeded at 25\% confluence, but a shorter overall time interval was used for the experiment. Three replicate plates were done, and plaque concentrations ranged from $25-100 \mu \mathrm{g} / \mathrm{ml} .200 \mu \mathrm{M}$

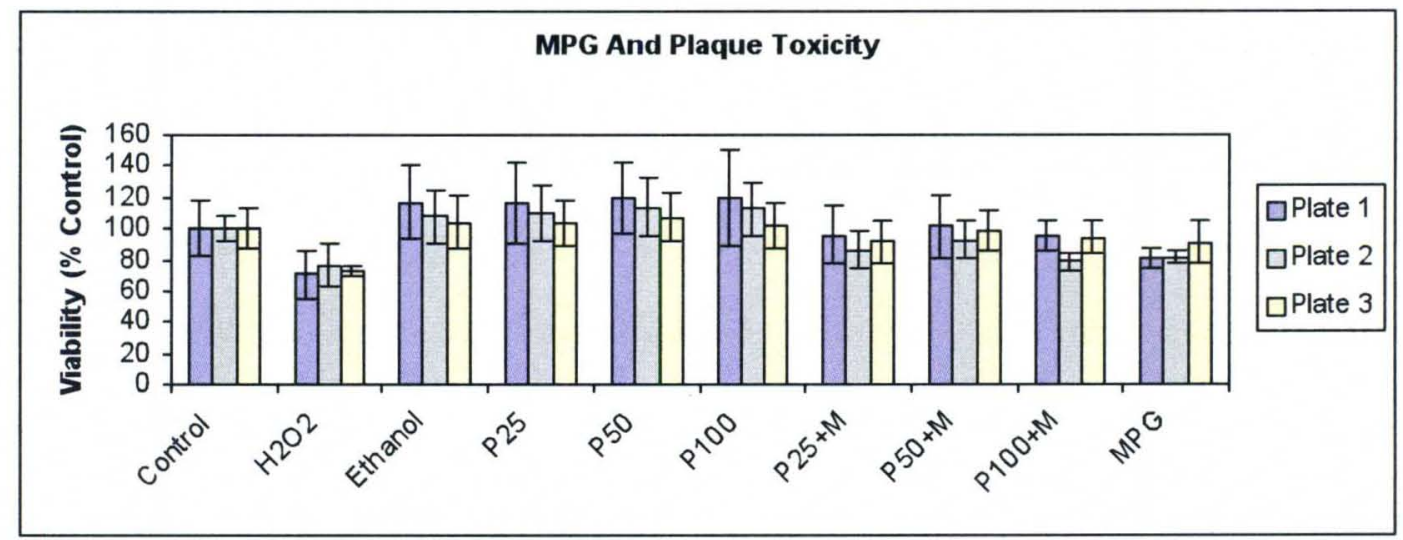

Figure 14 - 2.5h Alamar Blue 96-well plates were seeded at $25 \%$ confluence. Three replicate plates were done, and plaque concentrations ranged from $25-100 \mu \mathrm{g} / \mathrm{ml}$. Hydrogen Peroxide was $200 \mu \mathrm{M}$. $5 \mathrm{mM} \mathrm{MPG}$ was added to groups labeled M. Results are expressed as a percentage of the viability of control cells, based upon the degree of AlamarBlue reduction.

$\mathrm{H}_{2} \mathrm{O}_{2}$ was used due to anticipated depletion in the multipipette basin. Toxins were added just 8 hours after plate was seeded. If anything, wells treated with 5mM MPG fared 
worse, possibly due to the

short pre-incubation time.

The apparent stimulatory

effects of ethanol and plaque

are not well understood. At

the time the thinking was the

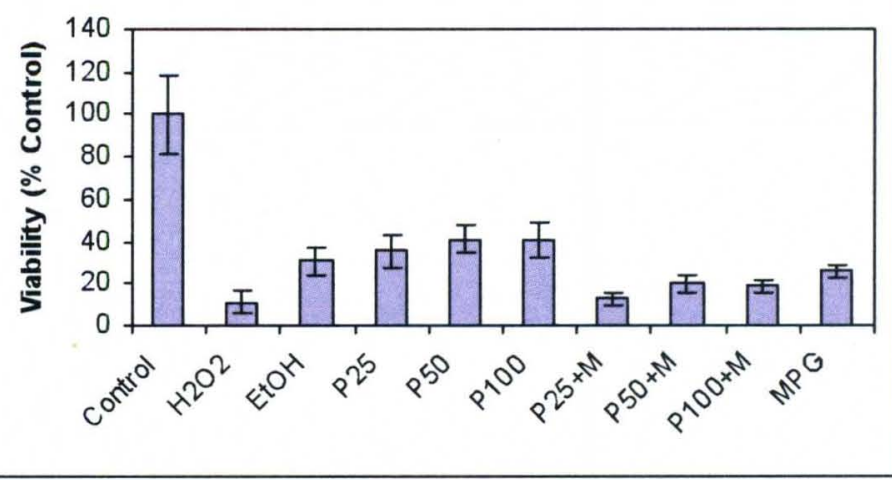

plate was still too confluent,

Figure 15 - 96 -well plates were seeded at $5 \%$ confluence. Cells were incubated with AlamarBlue for 3 hours before reading. Ethanol was $1 \%$ Wells were seeded at $5 \%$ confluence, grown for 24 hours and exposed to toxins for 48 hours. $5 \mathrm{mM}$ MPG was added to groups labeled M. The MPG

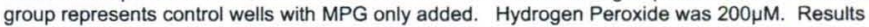
are expressed as a percentage of the viability of control cells, based upon the degree of

although the shorter-term AlamarBlue reduction.

nature of the experiment (under $48 \mathrm{~h}$ from seeding to read) was intended to alleviate that problem.

The subsequent experiment (Figure 15) was done using an even lower seeding

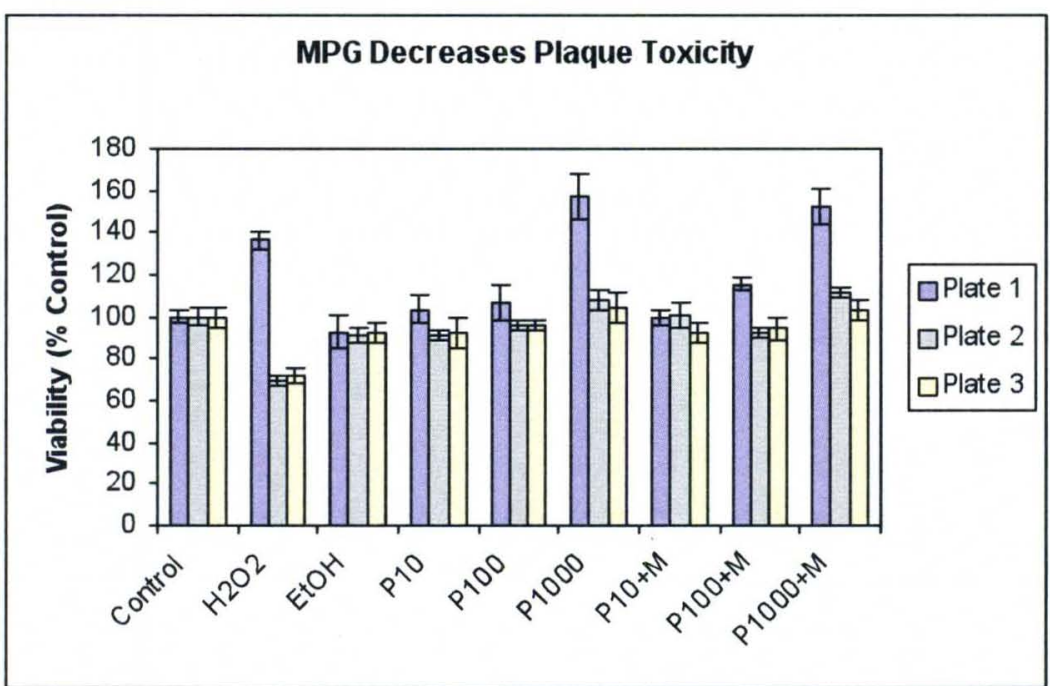

Figure 16 - MPG Affect on Plaque Toxicity - 96-well plates were seeded at $10 \%$ confluence. Cells were incubated with AlamarBlue for 3 hours before reading. Ethanol was $1 \%$ Wells were seeded at $10 \%$ confluence, grown for 24 hours and exposed to toxins for 48 hours. $5 \mathrm{mM} \mathrm{MPG}$ was added to groups labeled M. Hydrogen Peroxide was $200 \mu \mathrm{M}$. Results are expressed as a percentage of the viability of control cells, based upon the degree of AlamarBlue reduction. density in an attempt

to get a picture of the

longer-term effects on cell growth over two days, and to avoid the problems of wells getting overgrown before the assay was finished. Cells were

incubated with AlamarBlue for 3 hours before reading. Ethanol was only $1 \%$ Wells were seeded at $5 \%$ confluence, grown for 24 hours and exposed to toxins for 48 hours. Despite the fact that toxicity was clearly evident, even in the vehicle group, MPG still 
apparently had no protective effect under this scenario. In fact, it seemed harmful, probably considering the smaller number of cells while MPG concentration remained at $5 \mathrm{mM}$.

In order to strike a happy middle ground between too confluent and not confluent enough, we next seeded 396 -well plates at $10 \%$ confluence, with a strict $24 \mathrm{~h}$ regimen between seeding, adding toxins, and taking the reading (Figure 16). Another factor was new type III plaque homogenate (see Methods section above). Unfortunately, the carotid endarterectomy samples made available at the time were particularly devoid of soft plaque components. Thus the samples extracted were extremely contaminated with material from the vessel wall due to excessive scraping. Thus, the $1 \mathrm{mg} / \mathrm{ml}$ plaque concentration seems particularly intensive, yet actually reflects little plaque material. The apparent stimulatory effects in plate 1 are more than likely due to an abnormally low control group, due to problems with seeding density.

In order to see why we were not getting hardly any plaque toxicity with the new samples, we performed two final assays - a colony formation/clonogenic expansion assay and a very rigorous AlamarBlue experiment using a 24-well plate. In the clonogenic assay (Figure 17), we see stimulation at low plaque concentrations, deleterious effects at moderate-to-high doses. This

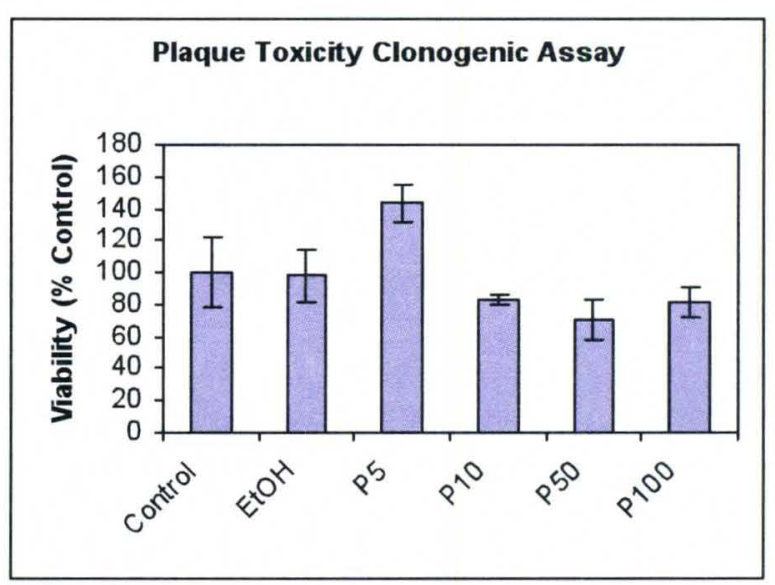

Figure $17-10 \mathrm{~cm}$ polystyrene tissue culture plates were seeded with 200 cells each and incubated in DMEM at $37^{\circ} \mathrm{C}$ for 5 days. Cells were then stained with Gentian Violet stain for 30 minutes. Plates were then scanned on an HP flatbed scanner. Colonies were counted in Adobe Photoshop software, using the pencil tool with a 50pixel contrasting yellow circle to mark each colony. As with all assays, error bars represent $95 \%$ confidence intervals. 
experimental system appears more sensitive than the AlamarBlue, which shows basically no effect in a straightforward plaque toxicity assay (Figure 18).

Our final experiment was a test for plaque toxicity, using type III homogenates

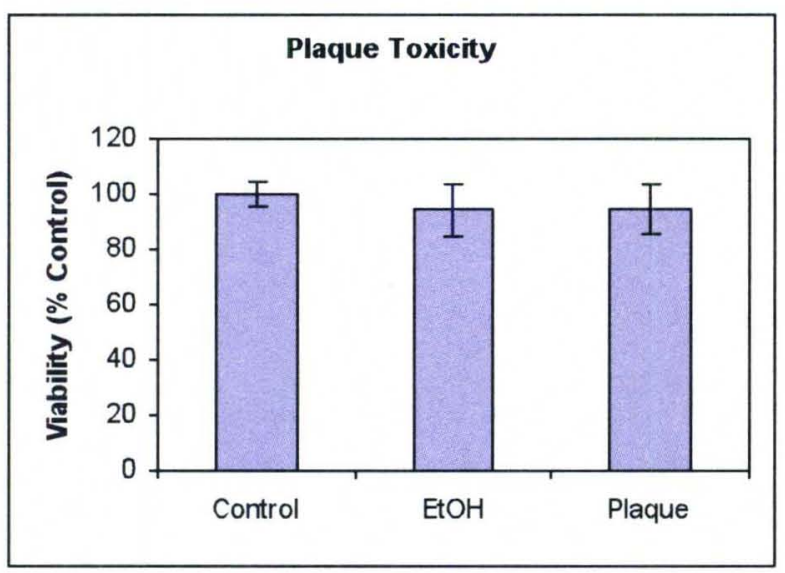

Figure 18 - Plaque Toxicity using type III homogenates. Results are expressed as a percentage of the viability of control cells, based upon the degree of AlamarBlue reduction. Homogenate was $750 \mu \mathrm{g} / \mathrm{ml}$ material - mostly non oxidized lipid. Results are expressed as a percentage of the viability of control cells, based upon the degree of AlamarBlue reduction. obtained from fresh samples, which were prepared immediately following collection from the OR. Cells were exposed to plaque approximately $1 \mathrm{hr}$ after I left the OR with the sample, and the plate was seeded at $2 \times 10^{\wedge} 5$ cells/ml, giving approx. $10 \%$ confluence for a 24-well plate. Wells

were close to $50 \%$ confluence at the time the cells were exposed, and as the ethanol group shows, they were sufficiently resistant at this density. $5 \mu \mathrm{l}$ of a $75 \mathrm{mg} / \mathrm{ml}$ homogenate was added to $500 \mu \mathrm{l}$ medium in the plaque group and $5 \mathrm{mcl}$ ethanol for that group. Cells were exposed for 4 hours, treated with Alamarblue, then read $4 \mathrm{~h}$ after that. These are the most optimal conditions we arrived at, judging from all of our previous experiments. The error bars outweigh the decreased viability, which is very slight to begin with. While not very exciting, this is consistent with the experiments completed up to this point. It seems like we have never been able to get decent toxicity out of the atherosclerotic material from carotid endarterectomies, and the very first experiments we did with more dilute samples were not much better.

Overall, our impression is that with these experimental models, toxicity is so slight it gets buried in the noise with even the most doggedly consistent handling, unless 
incredibly low seeding densities are used, at which point we have problems with vehicle and MPG toxicity. 


\section{DISCUSSION}

\section{Prospects of This Approach}

After more than 10 experiments with this experimental system, its drawbacks are obvious; there is a very fine line between vehicle toxicity and overgrown plates, giving a very narrow (less than 48 hours) window of opportunity for experimentation. Therefore the prospects of this approach appear somewhat limited. This appears to be a mainly problem with the sample preparation, however. Variation in the samples procured, together with changes in composition due to handling seem to outweigh the toxic effects seen when oxidized lipids hit the plaque. The clonogenic assay seemed the most free from experimental artifacts, and was apparently exquisitely sensitive to even the slightest levels of growth stimulation and toxicity. Also, using extreme numbers of replicates, as in our most successful experiment (Figure 13) enables slight effects to stand out from the noise. Regardless, a new source of atheroma material is obviously necessary. In previous successful experiments ${ }^{46}, 1.5 \mathrm{~g}$ samples of purely soft plaque gruel were obtainable. Such a source would apparently be necessary in order for such experiments to succeed as they have done in the past, or better yet, artificially oxidized lipids.

\section{Complimentary Approaches}

Wang et al. have demonstrated the efficacy of using isolated LDL from plasma to create OxLDL using $\mathrm{CuSO}_{4}{ }^{44}$ Using such a reliable model for toxicity, in conjunction with an assay for cell viability that does not involve redox reactions such as Trypan blue 
exclusion or Hoechst staining ${ }^{46}$ would probably be an excellent approach for future experimentation, especially for preliminary screening experiments such as these, although AlamarBlue seemed to work good enough in our hands for some of the experiments. Even more appropriately for drug candidate screens, an approach like that used by Wondrak et al. to use a screening method for direct, rapid detection of aldehyde quenchers ${ }^{1}$ would be an effective first step at arriving at a few good compounds worthy of further testing. 


\section{CONCLUSION}

While our hypothesis remains somewhat in question, there have been some indications that MPG may be protective (Figure 13). Also there are obvious toxicity issues, depending on seeding density of the macrophages (Figures 14 and 15), so it by no means represents the quintessential aldehyde-quenching drug. Despite the shortcomings of this experimental approach however, the overall concept of using antioxidant and carbonyl-quenching therapy to treat atherosclerosis is on solid ground, and is still an active area of research. ${ }^{47}$ Combination treatment with other therapies appears to be especially beneficial, both in regards to antioxidant therapy $y^{24,26,34}$ and conventional treatments with Statins and Omega-3 fatty acids ${ }^{48-51}$. Thus, it seems that finding an effective aldehyde-quenching agent for additional combined treatment of atherosclerosis ${ }^{45,46}$ would go a long way towards the elimination of heart disease as the leading cause of death in developed countries. 


\section{REFERENCES}

1. Wondrak GT, Cervantes-Laurean D, Roberts MJ, Qasem JG, Kim M, Jacobson EL, Jacobson MK. Identification of alpha-dicarbonyl scavengers for cellular protection against carbonyl stress. Biochem Pharmacol 2002;63:361-373.

2. Diaz MN, Frei B, Vita JA, Keaney JF, Jr. Antioxidants and atherosclerotic heart disease. N Engl J Med 1997;337:408-416.

3. Stary HC, Chandler AB, Dinsmore RE, Fuster V, Glagov S, Insull W, Jr., Rosenfeld ME, Schwartz CJ, Wagner WD, Wissler RW. A definition of advanced types of atherosclerotic lesions and a histological classification of atherosclerosis. A report from the Committee on Vascular Lesions of the Council on Arteriosclerosis, American Heart Association. Circulation 1995;92:1355-1374.

4. National Vital Statistics Reports. 56[5]. 2007. Ref Type: Generic

5. Davies MJ, Thomas AC. Plaque fissuring--the cause of acute myocardial infarction, sudden ischaemic death, and crescendo angina. Br Heart $J$ $1985 ; 53: 363-373$.

6. Gotto AM, Jr., Grundy SM. Lowering LDL cholesterol: questions from recent meta-analyses and subset analyses of clinical trial Datalssues from the Interdisciplinary Council on Reducing the Risk for Coronary Heart Disease, ninth Council meeting. Circulation 1999;99:E1-E7.

7. Stary HC, Blankenhorn DH, Chandler AB, Glagov S, Insull W, Jr., Richardson M, Rosenfeld ME, Schaffer SA, Schwartz CJ, Wagner WD, . A definition of the intima of human arteries and of its atherosclerosis-prone regions. A report from the Committee on Vascular Lesions of the Council on Arteriosclerosis, American Heart Association. Arterioscler Thromb 1992;12:120-134.

8. Hansson GK. Inflammation, atherosclerosis, and coronary artery disease. $N$ Engl $J$ Med 2005;352:1685-1695.

9. Stary HC, Chandler AB, Glagov S, Guyton JR, Insull W, Jr., Rosenfeld ME, Schaffer SA, Schwartz CJ, Wagner WD, Wissler RW. A definition of initial, fatty streak, and intermediate lesions of atherosclerosis. A report from the Committee on Vascular Lesions of the Council on Arteriosclerosis, American Heart Association. Circulation 1994;89:2462-2478. 
10. Stary HC. Evolution and progression of atherosclerotic lesions in coronary arteries of children and young adults. Arteriosclerosis 1989;9:I19-I32.

11. Steinberg D. Oxidative Modification of LDL in the Pathogenesis of Atherosclerosis. Am J Geriatr Cardiol 1993;2:38-41.

12. Herz J, Chen Y, Masiulis I, Zhou L. Expanding functions of lipoprotein receptors. J Lipid Res 2008.

13. Henriksen T, Mahoney EM, Steinberg D. Enhanced macrophage degradation of low density lipoprotein previously incubated with cultured endothelial cells: recognition by receptors for acetylated low density lipoproteins. Proc Natl Acad Sci U S A 1981;78:6499-6503.

14. Goldstein JL, Ho YK, Basu SK, Brown MS. Binding site on macrophages that mediates uptake and degradation of acetylated low density lipoprotein, producing massive cholesterol deposition. Proc Natl Acad Sci U S A 1979;76:333-337.

15. Quinn MT, Parthasarathy S, Steinberg D. Endothelial cell-derived chemotactic activity for mouse peritoneal macrophages and the effects of modified forms of low density lipoprotein. Proc Natl Acad Sci U S A 1985;82:5949-5953.

16. Haberland ME, Fless GM, Scanu AM, Fogelman AM. Malondialdehyde modification of lipoprotein(a) produces avid uptake by human monocytemacrophages. J Biol Chem 1992;267:4143-4151.

17. Haberland ME, Fong D, Cheng L. Malondialdehyde-altered protein occurs in atheroma of Watanabe heritable hyperlipidemic rabbits. Science 1988;241:215218.

18. Rajavashisth TB, Andalibi A, Territo MC, Berliner JA, Navab M, Fogelman AM, Lusis AJ. Induction of endothelial cell expression of granulocyte and macrophage colony-stimulating factors by modified low-density lipoproteins. Nature 1990;344:254-257.

19. Navab M, Imes SS, Hama SY, Hough GP, Ross LA, Bork RW, Valente AJ, Berliner JA, Drinkwater DC, Laks H, . Monocyte transmigration induced by modification of low density lipoprotein in cocultures of human aortic wall cells is due to induction of monocyte chemotactic protein 1 synthesis and is abolished by high density lipoprotein. J Clin Invest 1991;88:2039-2046.

20. Gosling J, Slaymaker S, Gu L, Tseng S, Zlot CH, Young SG, Rollins BJ, Charo IF. MCP-1 deficiency reduces susceptibility to atherosclerosis in mice that overexpress human apolipoprotein B. J Clin Invest 1999;103:773-778.

21. McMurray HF, Parthasarathy S, Steinberg D. Oxidatively modified low density lipoprotein is a chemoattractant for human T lymphocytes. J Clin Invest 1993;92:1004-1008. 
22. Griffith RL, Virella GT, Stevenson HC, Lopes-Virella MF. Low density lipoprotein metabolism by human macrophages activated with low density lipoprotein immune complexes. A possible mechanism of foam cell formation. $J$ Exp Med 1988;168:1041-1059.

23. Stocker R. Dietary and pharmacological antioxidants in atherosclerosis. Curr Opin Lipidol 1999; 10:589-597.

24. Meagher EA. Treatment of atherosclerosis in the new millennium: is there a role for vitamin E? Prev Cardiol 2003;6:85-90.

25. Zhao L, Pratico D, Rader DJ, Funk CD. 12/15-Lipoxygenase gene disruption and vitamin $\mathrm{E}$ administration diminish atherosclerosis and oxidative stress in apolipoprotein E deficient mice through a final common pathway. Prostaglandins Other Lipid Mediat 2005;78:185-193.

26. Stocker R. The ambivalence of vitamin $\mathrm{E}$ in atherogenesis. Trends Biochem Sci $1999 ; 24: 219-223$.

27. Rosenblat M, Volkova N, Coleman R, Aviram M. Anti-oxidant and antiatherogenic properties of liposomal glutathione: studies in vitro, and in the atherosclerotic apolipoprotein E-deficient mice. Atherosclerosis 2007;195:e61e68.

28. Martin HJ, Maser E. Role of human aldo-keto-reductase AKR1B10 in the protection against toxic aldehydes. Chem Biol Interact 2008.

29. Aldini G, le-Donne I, Facino RM, Milzani A, Carini M. Intervention strategies to inhibit protein carbonylation by lipoxidation-derived reactive carbonyls. Med Res Rev 2007;27:817-868.

30. Burcham PC, Kaminskas LM, Fontaine FR, Petersen DR, Pyke SM. Aldehydesequestering drugs: tools for studying protein damage by lipid peroxidation products. Toxicology 2002;181-182:229-236.

31. Shapiro HK. Carbonyl-trapping therapeutic strategies. Am J Ther 1998;5:323-353.

32. Neely MD, Zimmerman L, Picklo MJ, Ou JJ, Morales CR, Montine KS, Amaranth V, Montine TJ. Congeners of N(alpha)-acetyl-L-cysteine but not aminoguanidine act as neuroprotectants from the lipid peroxidation product 4hydroxy-2-nonenal. Free Radic Biol Med 2000;29:1028-1036.

33. Hsu CC, Yen HF, Yin MC, Tsai CM, Hsieh CH. Five cysteine-containing compounds delay diabetic deterioration in Balb/cA mice. $J$ Nutr 2004;134:32453249.

34. Odetti P, Pesce C, Traverso N, Menini S, Maineri EP, Cosso L, Valentini S, Patriarca S, Cottalasso D, Marinari UM, Pronzato MA. Comparative trial of N- 
acetyl-cysteine, taurine, and oxerutin on skin and kidney damage in long-term experimental diabetes. Diabetes 2003;52:499-505.

35. Levy RS, Fisher M, Alter JN. Penicillamine: review and cutaneous manifestations. J Am Acad Dermatol 1983;8:548-558.

36. Dolin DJ, Asplin JR, Flagel L, Grasso M, Goldfarb DS. Effect of cystine-binding thiol drugs on urinary cystine capacity in patients with cystinuria. $J$ Endourol $2005 ; 19: 429-432$.

37. vid-Vaudey E, Jamard B, Hermant C, Cantagrel A. Yellow nail syndrome in rheumatoid arthritis: a drug-induced disease? Clin Rheumatol 2004;23:376-378.

38. Zhang JG, Viale M, Esposito M, Lindup WE. Tiopronin protects against the nephrotoxicity of cisplatin in the rat. Hum Exp Toxicol 1999;18:713-717.

39. El-Missiry MA, Othman AI, Amer MA, bd el-Aziz MA. Attenuation of the acute adriamycin-induced cardiac and hepatic oxidative toxicity by $\mathrm{N}-(2-$ mercaptopropionyl) glycine in rats. Free Radic Res 2001;35:575-581.

40. Dost $\mathrm{T}$, Cohen MV, Downey JM. Redox signaling triggers protection during the reperfusion rather than the ischemic phase of preconditioning. Basic Res Cardiol $2008 ; 103: 378-384$.

41. Pezeshk A. The effects of ionizing radiation on DNA: the role of thiols as radioprotectors. Life Sci 2004;74:2423-2429.

42. Ayene SI, Kale RK, Srivastava PN. Radioprotective effect of 2mercaptopropionyl glycine on radiation-induced lipid peroxidation and enzyme release in erythrocytes. Int J Radiat Biol Relat Stud Phys Chem Med 1988;53:629639.

43. Ayene IS, al-Mehdi AB, Fisher AB. Inhibition of lung tissue oxidation during ischemia/reperfusion by 2-mercaptopropionylglycine. Arch Biochem Biophys 1993;303:307-312.

44. Wang Y, Qiao M, Mieyal JJ, Asmis LM, Asmis R. Molecular mechanism of glutathione-mediated protection from oxidized low-density lipoprotein-induced cell injury in human macrophages: role of glutathione reductase and glutaredoxin. Free Radic Biol Med 2006;41:775-785.

45. Li W, Dalen H, Eaton JW, Yuan XM. Apoptotic death of inflammatory cells in human atheroma. Arterioscler Thromb Vasc Biol 2001;21:1124-1130.

46. Li W, Ostblom M, Xu LH, Hellsten A, Leanderson P, Liedberg B, Brunk UT, Eaton JW, Yuan XM. Cytocidal effects of atheromatous plaque components: the death zone revisited. FASEB J 2006;20:2281-2290. 
47. Deigner HP, Hermetter A. Oxidized phospholipids: emerging lipid mediators in pathophysiology. Curr Opin Lipidol 2008;19:289-294.

48. Cannon CP. Combination therapy in the management of mixed dyslipidaemia. $J$ Intern Med 2008;263:353-365.

49. Davidson MH, Stein EA, Bays HE, Maki KC, Doyle RT, Shalwitz RA, Ballantyne CM, Ginsberg HN. Efficacy and tolerability of adding prescription omega-3 fatty acids $4 \mathrm{~g} / \mathrm{d}$ to simvastatin $40 \mathrm{mg} / \mathrm{d}$ in hypertriglyceridemic patients: an 8-week, randomized, double-blind, placebo-controlled study. Clin Ther 2007;29:1354-1367.

50. Maki KC, McKenney JM, Reeves MS, Lubin BC, Dicklin MR. Effects of adding prescription omega-3 acid ethyl esters to simvastatin ( $20 \mathrm{mg} /$ day) on lipids and lipoprotein particles in men and women with mixed dyslipidemia. Am J Cardiol 2008; 102:429-433.

51. Nambi V, Ballantyne CM. Combination therapy with statins and omega-3 fatty acids. Am J Cardiol 2006;98:34i-38i. 


\section{CURRICULUM VITAE}

NAME:

ADDRESS:

DOB:

EDUCATION

\& TRAINING:
Nason Paul Schooler

1601 East 80th Street \#9

Bloomington, Minnesota 55425

Cheyenne, Wyoming - January 21, 1974

B.S., Computer Science

Iowa State University

2001 